\title{
Molecular-Scale Interface Engineering of Nanocrystalline Titania by Co-adsorbents for Solar Energy Conversion
}

\author{
Mingkui Wang, ${ }^{[a, b]}$ Stefan Plogmaker, ${ }^{[c]}$ Robin Humphry-Baker, ${ }^{[b]}$ Peter Pechy, ${ }^{[b]}$ \\ Håkan Rensmo, ${ }^{*[c]}$ Shaik. M. Zakeeruddin, ${ }^{*[b]}$ and Michael Grätzel* ${ }^{*[b]}$
}

\begin{abstract}
The use of mixed self-assembled monolayers, combining hydrophobic co-adsorbents with the sensitizer, has been demonstrated to enhance the efficiency of dye-sensitized solar cells (DSCs). Herein, the influence of the anchoring groups of the co-adsorbents on the performance of the DSCs is carefully examined by selecting two model molecules: neohexyl phosphonic acid (NHOOP) and bis-(3,3-dimethyl-butyl)-phosphinic acid (DINHOP). The effect of these co-adsorbents on the pho-
\end{abstract}

tovoltaic performance ( $J-V$ curves, incident photon-to-electron conversion efficiency) is investigated. Photoelectron spectroscopy and electrochemical impedance spectroscopy are performed to assess the spatial configuration of adsorbed dye and co-adsorbent molecules. The photoelectron spectroscopy studies indicate that the ligands of the ruthenium complex, containing thiophene groups, point out away from the surface of $\mathrm{TiO}_{2}$ in comparison with the NCS group.

\section{Introduction}

Over the last two decades there has been an increasing demand for renewable energy sources that can replace fossil fuels. Photovoltaic devices are attractive candidates as they directly convert solar energy into electrical energy upon illumination. The currently used photovoltaic (PV) cells, based on single-crystalline silicon, have a rather high efficiency $(25 \%)^{[1]}$ but they are expensive due to the material consumption and the high costs of production. As an alternative, the so-called organic photovoltaic (OPV) cells, including dye-sensitized, ${ }^{[2]}$ polymer, ${ }^{[3]}$ and small-molecule cells, ${ }^{[4]}$ are presently under active investigation. Dye-sensitized solar cells (DSCs) fabricated using transparent metal oxide electrodes have received significant attentions owing to their potential for improved lifetime and performance compared to conventionally organic solar cells.

At the heart of a DSC is a mesoscopic wide-band gap oxide film covered by a monolayer of sensitizer or semiconductor quantum dots forming a "bulk" junction with a hole conductor or electrolyte that is infiltrated in the porous space. Respectable photon-to-current conversion efficiencies of around 11 $13 \%$ are reported for DSC devices. ${ }^{[5]}$ Significant efforts towards efficiency enhancement have been directed at the synthesis of new materials and fundamental studies to understand the nature of charge-carrier generation and loss channels. It is well-known that the interface properties at the heterojunction depend on the nature of the sensitizer and the co-adsorbents. Charge carrier recombination is retarded by the formation of an insulating barrier in the case of dye/co-adsorbent (compared dye alone), thus enhancing electron collection in the nanocrystalline titania film. Meanwhile, surface trap states can be formed during the sensitization process when anchoring groups react onto a metal oxide surface, which augments interfacial charge-carrier recombination. Hence, it is important to investigate the influence of anchoring groups on DSC device performance. Photoelectron spectroscopy (PES) is a technique to gain insight information on the surface binding of sensitizers and electronic structure, ${ }^{[9]}$ and is able to identify all elements present on a surface and their relative quantities with a probe depth in the order of $1 \mathrm{~nm}$. Specifically, PES can give element-specific information that can be used to measure relative surface concentrations in a mixed molecular layer of, for example, dyes and co-adsorbents adsorbed onto a titania surface. It is used here to obtain information on molecular configurations, as will be discussed further below.

[a] Dr. M. Wang

Michael Grätzel Center for Mesoscopic Solar Cells

Wuhan National Laboratory for Optoelectronics

College of Optoelectronic Science and Engineering

Huazhong University of Science and Technology

1037 Luoyu Road, Wuhan 430074 (PR China)

[b] Dr. M. Wang, Dr. R. Humphry-Baker, Dr. P. Pechy, Dr. S. M. Zakeeruddin, Prof. M. Grätzel

Laboratory for Photonics and Interfaces

Swiss Federal Institute of Technology

1015, Lausanne (Switzerland)

Fax: (+41) 21-6934111

E-mail:shaik.zakeer@epfl.ch michael.graetzel@epfl.ch

[c] S. Plogmaker, Prof. H. Rensmo

Molecular and Condensed Matter Physics

Department of Physics and Astronomy

Uppsala University

Box 516, 75120 Uppsala (Sweden)

E-mail: hakan.rensmo@physics.uu.se

Supporting Information for this article is available on the WWW under http://dx.doi.org/10.1002/cssc.201100549. 


\section{Results and Discussion}

In the present work, bis-(3,3-dimethyl-butyl)-phosphinic acid (DINHOP) and neohexyl phosphonic acid (NHOOP) were used as co-adsorbents in DSC devices. In our earlier study,<smiles>CC(C)(C)CCP(=O)(O)CCC(C)(C)CCP(=O)(O)O[N+](=O)[O-]</smiles>

DINHOP ${ }^{[10]}$ and decylphosphonic acid ${ }^{[11]}$ were used as a co-adsorbent in conjunction with Z907Na dye in DSCs, and found to exert a positive influence on the device performance and longterm stability through a substantial reduction of the charge recombination rate. Herein, NHOOP was chosen as a simple analogue for DINHOP in order to better understand the influence of the amphiphlic chain and anchoring group moieties on the photovoltaic parameters of DSCs. There are two structural differences between the DINHOP and NHOOP molecules: DINHOP has two hydrophobic neohexyl chains and the anchoring group is phosphinic acid $\left(-\mathrm{PO}_{2} \mathrm{H}\right)$, whereas in NHOOP there is only one hydrophobic neohexyl chain and the anchoring group is phosphonic acid $\left(-\mathrm{PO}_{3} \mathrm{H}_{2}\right)$.

Two representative PES survey spectra are shown in Figures $1 \mathrm{a}$ and $\mathrm{b}$, one of $\mathrm{a} \mathrm{TiO}_{2}$ sample sensitized with a mixture of dye and co-adsorbent (here: DINHOP) and one of a sample sensitized with only dye molecules, respectively. In the former, the ratio of dye to co-adsorbent was set at 4:1 in a mixture of acetonitrile and tert-butyl alcohol $(1: 1, v / v)$. The regions originating from the $\mathrm{TiO}_{2}$ substrate (O1s and $\mathrm{Ti} 2 \mathrm{p}$ ), from the dye (N 1s, C 1s, Ru 3d, and S2p) and from the co-adsorbent (C1s and $\mathrm{P} 2 \mathrm{p}$ ) are indicated. High-resolution spectra of the $\mathrm{C} 1 \mathrm{~s}$ and Ru $3 d$ core levels of the same samples are shown in Figure 2. The two samples studied here have nearly-symmetric Ru 3d5/2 signals (at about $280.6 \mathrm{eV}$ ), and the energy positions and full width at half maximum values of these signals are similar. The sample containing a mixture of dye and co-adsorbent shows a lower intensity (almost 10\%), indicating a lower amount of dye. A similar effect was observed for the $\mathrm{C} 1 \mathrm{~s}$ peak, with the main peak at about $285.0 \mathrm{eV}$. This result shows that the amount of dye at the surface decreases with the co-adsorbents (see Supporting Information), but no significant changes in energy matching between the dye (as measured by Ru 3d5/2) and the substrate (measured from Ti2p3/2) can be observed.

Figure 3 compares the high resolution $\mathrm{N} 1 \mathrm{~s}$ and $S 2 p$ spectra of the same samples, and reveals many similarities. Both samples show two well-resolved peaks in the $\mathrm{N} 1 \mathrm{~s}$ region (Figure $3 \mathrm{a}$ ), originating from the two nitrogen atoms in the NCS groups (at $397.7 \mathrm{eV}$ ) and the four nitrogen atoms in the coordinating bipyridine ligands (at $399.5 \mathrm{eV}$ ). These spectra were energy-calibrated relative to $\mathrm{Ti} 2 \mathrm{p}$ in order to better compare their shape, while the intensity was

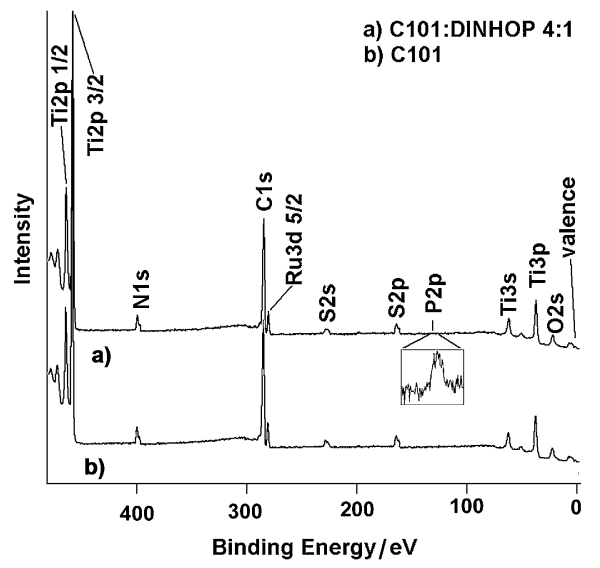

Figure 1. Typical PES spectra obtained for $\mathrm{TiO}_{2}$ samples sensitized with a) a mixture of dye and co-adsorbent, and b) dye alone.

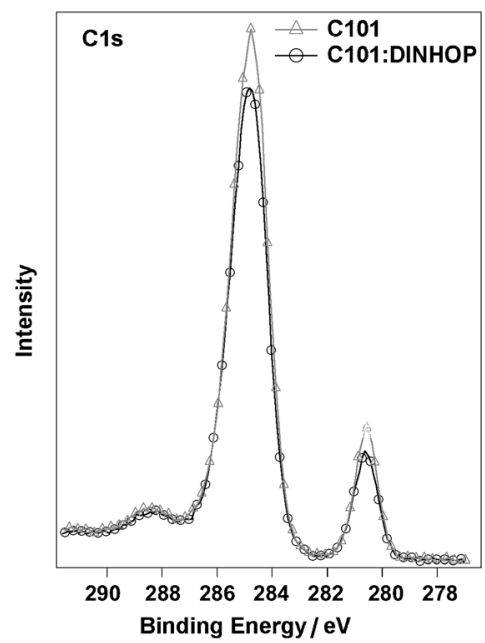

Figure 2. $\mathrm{C} 1 \mathrm{~s}$ signal originating from $\mathrm{TiO}_{2}$ substrate sensitized with dye molecule and co-adsorbent (DINHOP). Energy and intensity calibrated versus Ti2p. 
calibrated with respect to the maximum intensity. The intensity ratios between the peaks $(397.7 \mathrm{eV}$ and $399.5 \mathrm{eV}$ ) of the sample sensitized with only dye molecules and the sample obtained from a mixture of dye and co-adsorbent are close to 0.39:1 and 0.43:1 for C101/DINHOP and C101/NHOOP, respectively. Both values are slightly lower than the ratio of $0.5: 1$ expected from the molecular formula of the $\mathrm{C} 101$ sensitizer. ${ }^{[7]}$ Such variations may be expected for well-organized surface layers. This discrepancy is attributed to the difference in scattering probability of photo-emitted $\mathrm{N} 1 \mathrm{~s}$ electrons from the different nitrogen atoms in the molecule. Such differences are due to different attenuations that reflect the position of the atoms in the different molecular layers. The slightly lower ratios of nitrogen in thiocyanate compared to nitrogen in pyridine may therefore be explained by a larger damping of the signals from nitrogen in the pyridine. Specifically, the values 0.39:1 and $0.43: 1$ are below $0.5: 1$, which indicates that on average the nitrogen atoms in thiocyanate groups are forced towards the $\mathrm{TiO}_{2}$ surface. This is probably an effect caused by the bulky 5-hexylthiophen sticking out from the surface (see below). This shielding is slightly more pronounced for C101 with DINHOP. When comparing the N1s dye spectra of samples with NHOOP as co-adsorbent and DINHOP as co-adsorbent, no differences in the shape of the spectra were found.

Figure $3 b$ shows the $S 2 p$ spectral region of the same samples. The structure of the $S 2 p$ spectra of $\mathrm{C} 101$ is built up by spin-orbit-split doublets (S2p1/2 and S2p3/2) having an intensity ratio of $1: 2$ and a peak split of $1.18 \mathrm{eV}$. From the molecular formula, two distinguishable spin-orbits split doublets are expected, originating from the NCS and the thiophene, respectively. Indeed this is observed for both samples, with one doublet from the NCS group with the S2p3/2 peak at about $162 \mathrm{eV}$ and one doublet from the thiophene with the S2p3/2 peak position about $164 \mathrm{eV}$. Interestingly, the intensity ratio (obtained from curve fitting, data not shown) of about 0.66:1 instead of 1:1 clearly indicates that the ligands containing the thiophene units point out from the surface in comparison with the NCS group, concomitant with the findings obtained from the N1s spectra discussed above. Although the spectra of the mixed samples show many similarities to those of the dye only, the spectra from the samples with co-adsorbents are somewhat less resolved. Thus, although the differences are small, the experiments indicate that the mixed surface has a slightly larger fraction of dye molecules with different surface configuration.

A detailed surface analysis of nine different samples was made using PES, with special emphasis on determining the amounts of co-adsorbent and dye. The results are shown in Tables 1 and 2. The PES signals include the Ru3d5/2 (originating from the ruthenium atoms in the dye, Supporting Information Figure $\mathrm{S} 1$ ) and $\mathrm{P} 2 \mathrm{p}$ peaks (originating from the phosphor atom in the phosphonic and phosphinic acid anchoring groups of NHOOP and DINHOP, respectively). Table 1 compares the amounts of dye coverage on the $\mathrm{TiO}_{2}$ surface, quantified by measuring the Ru $3 d$ signal versus the Ti $2 p$ substrate signal and comparing the different values to that obtained for the sample sensitized for $24 \mathrm{~h}$ with dye only. In the case of dye/

\begin{tabular}{|llll|}
\hline \multicolumn{3}{|l|}{ Table 1. Dye coverage in comparison to C101 sensitized for 24 $\mathrm{h}$} \\
\hline System & $\begin{array}{l}\text { Ru3d/Ti2 } \mathrm{p} \text { ratio } \\
\text { 100 s }\end{array}$ & $30 \mathrm{~min}$ & $24 \mathrm{~h}$ \\
\hline C101 & 0.57 & 0.83 & 1.00 \\
C101-DINHOP & 0.53 & 0.78 & 0.89 \\
C101-NHOOP & 0.44 & 0.67 & 0.66 \\
\hline
\end{tabular}

\begin{tabular}{|c|c|c|c|c|}
\hline \multirow[t]{2}{*}{ Device } & \multirow[t]{2}{*}{ System } & \multicolumn{3}{|c|}{ Relative amount [\%] } \\
\hline & & $100 \mathrm{~s}$ & $30 \mathrm{~min}$ & $24 \mathrm{~h}$ \\
\hline \multirow[t]{2}{*}{ A } & C101 & 84 & 78 & 82 \\
\hline & DINHOP & 16 & 22 & 18 \\
\hline \multirow[t]{2}{*}{ B } & C101 & 52 & 43 & 40 \\
\hline & NHOOP & 48 & 57 & 60 \\
\hline
\end{tabular}

DINHOP, after a long dye dipping time ( $24 \mathrm{~h}$ ), the dye coverage is reduced to 0.89 , while this value is largely reduced to 0.66 when NHOOP was used. The amount of dye with respect to the amount of co-adsorbent was measured using the Ru3d5/2 (the dye quantity) and the $\mathrm{P} 2 \mathrm{p}$ signals (the co-adsorbent quantity). The results are shown in Table 2 . For DINHOP, the co-adsorbent concentration is around $20 \%$, independent of time, but when using NHOOP as co-adsorbent the concentration varies with time and reaches a maximum of $60 \%$.

Based on the value determined for the decrease in C101 coverage and relative amounts of co-adsorbent versus C101 it is possible to estimate how many co-adsorbents replace each dye molecule. For example, the co-adsorption of NHOOP removes 34 out of 100 dye molecules and replaces these with $0.66 \times(60 / 40)=99$ NHOOP molecules. That is, about three NHOOP molecules replace each dye molecule. For the co-adsorption of C101/DINHOP only two DINHOP molecules replace each dye molecule. This difference fits well to what one would expect from the molecular structures, with DINHOP being bulkier than NHOOP (ratio about 3 to 2 ) but less bulky than the C101 dye.

Figure 4 a shows absorption spectra of sensitizer C101 with and without co-adsorbents adsorbed onto a nanocrystalline $6 \mu \mathrm{m}$ thick $\mathrm{TiO}_{2}$ film with different dipping time. In order to compare the adsorption kinetics of dye with co-adsorbents, we monitored the change in absorbance at $\lambda=540 \mathrm{~nm}$ of identical $6 \mu \mathrm{m}$ thick $\mathrm{TiO}_{2}$ films (Figure S2). The absorbance increases until it reaches a plateau after $7 \mathrm{~h}$, as illustrated for the case of C101 alone (Figure S2). A dye-sensitized $\mathrm{TiO}_{2}$ film co-grafted with either DINHOP or NHOOP showed a similar absorption spectrum. In the case of C101/DINHOP, the absorbance at around $540 \mathrm{~nm}$ decreased by $18 \%$ compared to that of $\mathrm{C} 101$ alone. The competition between DINHOP and the dye C101 in binding to the $\mathrm{TiO}_{2}$ surface is responsible for the decrease in dye adsorption. In the case of C101/NHOOP, characteristic metal-to-ligand charge transfer absorption bands in the visible region are red-shifted by $12 \mathrm{~nm}$ compared to C101 alone or C101/DINHOP, as illustrated in Figure $4 \mathrm{a}$. The adsorbed 

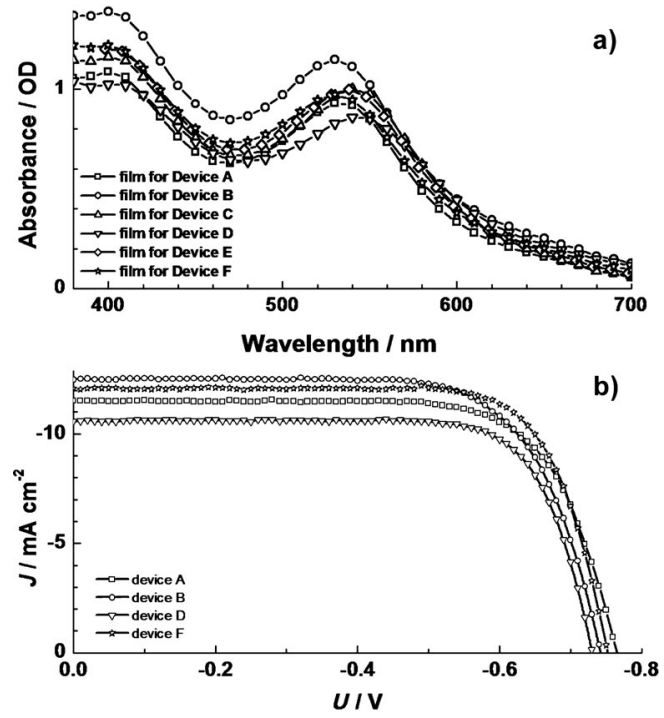

Figure 4. a) UV/Vis absorption spectra of a $6 \mu \mathrm{m}$ thick film comprising $\mathrm{TiO}_{2}$ particles of $20 \mathrm{~nm}$ in size, sensitized with C101 with and without co-adsorbent, and b) $J-V$ characteristics of different devices prepared under different conditions, measured as indicated in Table 3 at $100 \mathrm{~mW} \mathrm{~cm}^{-2}$.

amounts of dye on the $\mathrm{TiO}_{2}$ film with and without co-adsorbents are listed in Table 3. The amount $m_{\text {dye }}$ adsorbed onto the $\mathrm{TiO}_{2}$ surface was largely reduced in the presence of NHOOP as compared to that without co-adsorbent in the dye bath, the difference being about $37 \%$ or $27 \%\left[\left(\mathrm{~m}_{\text {dye, alone }}-\mathrm{m}_{\text {dye, co-adsorbent }}\right) /\right.$ $\mathrm{m}_{\text {dye, alone }}=27 \%$; this value is about $19 \%$ in the case of DINHOP]. This result is attributed to the different anchoring groups of the co-adsorbents, that is, phosphonic acid for NHOOP and phosphinic acid for DINHOP. These values are similar to the values obtained with PES (Table 1 showing 33 and $22 \%$ respectively) for samples sensitized for $30 \mathrm{~min}$. For samples sensitized for longer times, the values for DINHOOP differ slightly more, which is probably due to the longer time needed to reach complete monolayer equilibrium throughout the mesoporous film. The dye adsorption onto the nanocrystalline $\mathrm{TiO}_{2}$ surface was monitored by the absorbance as a function of time as presented in Figure $\mathbf{S}$, showing a relatively fast rate of dye adsorption in the first $1 \mathrm{~h}$ of dipping time. This result is consistent with that from PES investigations (Tables 1 and 2). The trend observed when comparing the PES measurements obtained for $100 \mathrm{~s}, 30 \mathrm{~min}$, and $24 \mathrm{~h}$ show that the dynamics of formation of the equilibrated state of the mixed surface layer is probably much longer than $30 \mathrm{~min}$.

\begin{tabular}{|c|c|c|c|c|c|c|c|}
\hline Device & System & $\begin{array}{l}\text { Dipping } \\
\text { time }\end{array}$ & $\begin{array}{l}V_{\text {oc }} \\
{[\mathrm{mV}]}\end{array}$ & $\begin{array}{l}J_{\mathrm{sc}} \\
{\left[\mathrm{mAcm}^{-2}\right]}\end{array}$ & $F F$ & $\begin{array}{l}H \\
{[\%]}\end{array}$ & $\begin{array}{l}\text { Dye loading } \\
{\left[10^{-8} \mathrm{~mol} \mathrm{~cm}^{-2}\right]}\end{array}$ \\
\hline A & C101 & $30 \mathrm{~min}$ & 765 & 11.60 & 0.72 & 6.4 & 5.25 \\
\hline B & C101 & $18 \mathrm{~h}$ & 742 & 12.56 & 0.71 & 6.6 & 6.86 \\
\hline C & C101-NHOOP & $90 \mathrm{~min}$ & 759 & 11.22 & 0.74 & 6.3 & - \\
\hline D & C101-NHOOP & $18 \mathrm{~h}$ & 731 & 10.65 & 0.76 & 5.9 & 5.00 \\
\hline $\mathrm{E}$ & C101-DINHOP & $90 \mathrm{~min}$ & 759 & 11.69 & 0.74 & 6.6 & - \\
\hline $\mathrm{F}$ & C101-DINHOP & $18 \mathrm{~h}$ & 752 & 12.15 & 0.75 & 6.9 & 5.53 \\
\hline
\end{tabular}

The influence of these co-adsorbents on the photovoltaic device parameters, that is, open-circuit voltage $\left(V_{\text {oc }}\right)$, shortcircuit current $\left(J_{\text {sc }}\right)$, and fill factor $(F F)$, is remarkable. The $J-V$ characteristics of devices A, B, D, and F (see Table 3 for a description of devices A-F) are depicted in Figure $4 \mathrm{~b}$. Detailed photovoltaic parameters and photovoltaic conversion efficiency $(\eta)$ values for devices A-F are shown in Table 3.

Interestingly, the $J_{\mathrm{sC}}, V_{\mathrm{oc}}$, and FF values of device $\mathrm{F}$ (C101) DINHOP) are $12.15 \mathrm{mAcm}^{-2}, 750 \mathrm{mV}$, and 0.75 , respectively. This yields an overall power conversion efficiency (PCE) of $6.9 \%$, higher than that of device $\mathrm{B}$, employing $\mathrm{C} 101$ alone $(6.6 \%)$. Changing the co-adsorbent from DINHOP to NHOOP (using the same electrolyte) in device $D$ (Figure $4 \mathrm{~b}$ ) resulted in a $5.9 \%$ overall $P C E$, resulting principally from the lower photocurrent. The decrease of the photocurrent is ascribed to the reduced dye loading on the surface of the $\mathrm{TiO}_{2}$ film resulting from the competition of NHOOP adsorption with that of C101 (Figure $4 \mathrm{a}$ ). Although the dye loading is also reduced in the case of C101/DINHOP, device F shows a smaller decrease of the photocurrent than device $D$, which is likely the result of a better electron collection efficiency by the DINHOP co-adsorbent. In this study, a $6 \mu \mathrm{m}$ thick $\mathrm{TiO}_{2}$ transparent film was used, explaining the lower photocurrents and solar to electric power conversion efficiencies compared to the values reported earlier (PCE $>11 \%$ ), in which a reflective (scattering) layer comprising large titania particles was applied. ${ }^{[7]}$ By controlling the dye loading time (30 min for C101 for device A, 90 min for C101/ NHOOP for device $C$ and C101/DINHOP for device E), similar absorbance of the sensitized $\mathrm{TiO}_{2}$ film was set, as presented in Figure $4 \mathrm{a}$. Thus, photocurrents of $11.6,11.2$, and $11.7 \mathrm{~mA} \mathrm{~cm}^{-2}$, respectively, were obtained without change in the $V_{\text {oc }}$ (about $760 \pm 5 \mathrm{mV}$; see Table 3 ). In this case, the surface coverage due to the dye adsorbed onto the $\mathrm{TiO}_{2}$ nanoparticles is similar for all three devices, but there is some free unsensitized area for device $A$, being partially occupied by NHOOP for device B or by DINHOP for device $C$ as discussed above. The incident photon to current conversion efficiency (IPCE) values for devices utilizing the sensitizer $\mathrm{C} 101$ with and without co-adsorbents are shown in Figure S3. A longer dye dipping time increases the IPCE response of the devices (as comparison devices $A$ and $B$ ).

Although sufficient information on the surface and optical properties of the dye-sensitized $\mathrm{TiO}_{2}$ nanocrystalline films can be obtained by PES and UV/Vis spectroscopy, the electronic features of the mesoscopic oxide film, such as its electron transport and interfacial recombination features, can not be easily induced from the complex analysis of the chemical adsorption data. Impedance analysis has therefore been used to monitor photovoltaic parameter changes in various devices. $^{[8,12-14]}$ Using the transmission line model, important figures of merit, such as electron diffusion resistance $\left(R_{\mathrm{t}}\right)$ and recombination resistance $\left(R_{\mathrm{ct}}\right)$ 
were derived by fitting the impedance data. The apparent recombination lifetime $\left(\tau_{n}\right)$ was calculated [Equation (1)]. The electron transfer resistance depends on the density of electrons $\left[n_{\mathrm{cb}}\right.$, Equation (2)] in the conduction band (CB) and mobility $\left[\mu_{\mathrm{e}}\right.$, the free-electron diffusion coefficient according to the Einstein relation on diffusion of charged particles, see Equation (3)]. The resistance $R_{\mathrm{t}}$ can be described by Equation (4), where $R_{0}$ [Equation (5)] is the film resistance at the applied bias [Equation (6)] when the electron Fermi level $\left(E_{F, n}\right)$ matches the conduction band edge $\left(E_{\mathrm{cb}}\right)$, and $E_{\mathrm{F}, \text { redox }}$ is the equilibrium potental of redox couple in the electrolyte.

$\tau_{\mathrm{n}}=R_{\mathrm{ct}} C_{\mu}$

$n_{\mathrm{cb}}=N_{\mathrm{cb}} \exp \left(\left(E_{\mathrm{F}, n}-E_{\mathrm{cb}}\right) /\left(k_{B} T\right)\right)$

$\mu_{\mathrm{e}}=\left(D_{\mathrm{e}} q\right) /\left(k_{\mathrm{B}} T\right)$

$R_{\mathrm{t}}=\frac{k_{\mathrm{B}} T N_{\mathrm{cb}}}{q^{2} D_{\mathrm{e}}} \exp \left(-\frac{E_{\mathrm{F}, \mathrm{n}}-E_{\mathrm{cb}}}{k_{\mathrm{B}} T}\right)$

$=R_{0} \exp \left(\frac{E_{\mathrm{cb}}-E_{\mathrm{F}, \text { redox }}}{k_{\mathrm{B}} T}\right) \exp \left(-\frac{U}{k_{\mathrm{B}} T}\right)$

$R_{0}=\left(k_{\mathrm{B}} T N_{\mathrm{cb}}\right) /\left(q D_{\mathrm{e}}\right)$

$U=E_{\mathrm{F}, n}-E_{\mathrm{F}, \text { redox }}$

In Equation (4), the first term on the right-hand side represents the influence of charge mobility related to the trapping and de-trapping of electrons from states in the band gap, the second term is the influence of the position of the lower edge of the $C B$, and the third term results from the applied potential on the sensitized $\mathrm{TiO}_{2}$ electrode. Figure 5 a shows the effect of the applied voltage on the electron transport resistance $R_{\mathrm{t}}$ under dark conditions for the various devices. The logarithm of the electron transport resistance shows parallel behavior for various devices. The shifts of the resistances for the steadystate electron transport in those devices is attributed to a change in the position of the conduction band edge $\left(E_{\mathrm{cb}}\right)$ and/ or the free electron mobility $\left(\mu_{\mathrm{e}}\right) .^{[13,15]}$ Using photoanodes of similar absorbance by controlling the dipping time (see Table 1), the $R_{\mathrm{t}}$ data from the fresh devices C and E (C101) NHOOP or (101/DINHOP) are down-shifted from those of the fresh device $A$ (C101 alone). It is interesting to note that device $D$ (with NHOOP) has the largest electron diffusion resistance at identical bias, compared to devices $B$ and $F$, when a long dipping time was used. As discussed from the PES and UV/Vis spectroscopy investigations, the exposed $\mathrm{TiO}_{2}$ nanoparticles area in device D was almost completely covered by NHOOP. The augmented resistance reflects a slow electron diffusion process due to surface traps, induced by the strong binding of phosphonic acid to the $\mathrm{TiO}_{2}$ surface. In general, on a metal oxide surface, the binding strength of phosphonic acid is higher than that of carboxylic acid. For devices with C101/ NHOOP, an increased loading of co-adsorbent was found when increasing the dipping time.

The interfacial electron transfer resistance $\left(R_{\mathrm{ct}}\right)$ corresponds to electrons in either the conduction band or in surface states transferring to the oxidized form of redox couple in the elec-
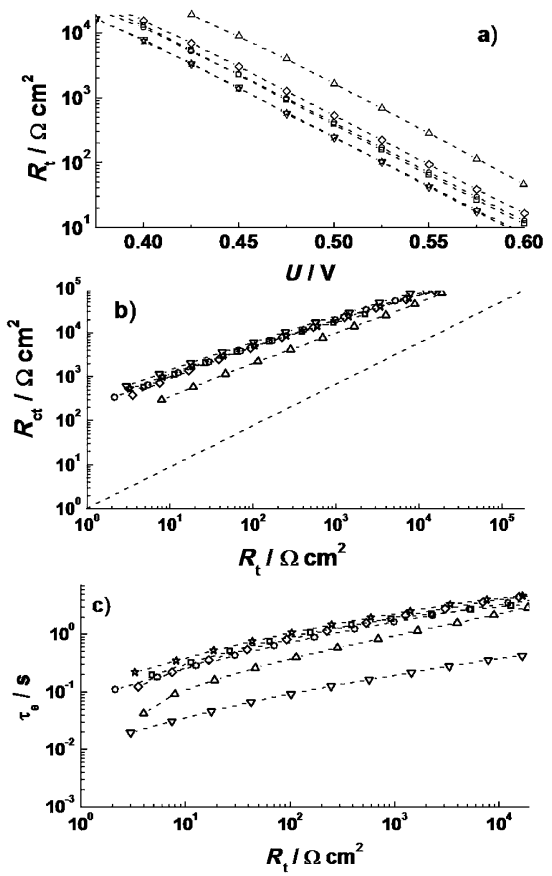

Figure 5. Derived equivalent circuit components obtained from impedance measurements under dark conditions at $20^{\circ} \mathrm{C}$ for different devices $\mathrm{A}-\mathrm{F}$ (see Table 3), sensitized with: $\square, 0, C 101 ; \triangle, \nabla, C 101-N H O O P$; and $\diamond, \star: C 101 /$ DINHOP. a) Electron transport resistance in the $\mathrm{TiO}_{2}$ film as a function of bias, b) recombination resistance $\left(R_{\mathrm{ct}}\right)$, and c) the apparent recombination electron lifetime $\left(\tau_{n}\right)$ as a function of $R_{\mathrm{t}}$.

trolyte (in this case: $\mathrm{I}_{3}^{-}{ }^{-} \cdot{ }^{[17]}$ For the interfacial recombination reaction $\left(\mathrm{I}_{3}^{-}+2 \mathrm{e}_{\mathrm{cb}}{ }^{-} \rightarrow 3 \mathrm{I}^{-}\right)$, without mass-transfer limitations, the relationship between the dark current density (reflecting charge transfer from electrons that occupy states in the conduction band or surface states in the semiconductor to unoccupied electronic states in the electrolyte) and the over-potential $(\eta)$ on the sensitized electrode can be described by the Butler-Volmer equation: $:^{[18]}$

$R_{\mathrm{ct}}=R_{\mathrm{ct}, 0} \exp \left(-\beta \frac{\eta}{k_{\mathrm{B}} T}\right)=R_{\mathrm{ct}, 0} \exp \left(-\beta \frac{\left(E_{\mathrm{F}, \mathrm{n}}-E_{\mathrm{F}, \text { redox }}\right)}{k_{\mathrm{B}} T}\right)$

By introducing Equation (4), Equation (7) can be rewritten as

$$
\begin{aligned}
& R_{\mathrm{ct}}=R_{\mathrm{ct}, 0} \exp (\beta)\left(R_{\mathrm{t}} / R_{\mathrm{t}, 0} \exp \left(\frac{E_{\mathrm{cb}}-E_{\mathrm{F}, \text { redox }}}{k_{\mathrm{B}} T}\right)\right) \\
& =R_{\mathrm{ct}, 0}^{\prime} \exp \left(-\beta \frac{E_{\mathrm{cb}}-E_{\mathrm{F}, \text { redox }}}{k_{\mathrm{B}} T}\right) R_{\mathrm{t}}
\end{aligned}
$$

Figure $5 \mathrm{~b}$ presents the overall recombination resistance $\left(R_{\mathrm{ct}}\right)$ to charge transfer at the $\mathrm{TiO}_{2}$ /electrolyte interface as a function of electron diffusion resistance $\left(R_{\mathrm{t}}\right)$. As the electron transfer resistance $R_{\mathrm{t}}$ decreases, the recombination resistance $R_{\mathrm{ct}}$ decreases, due to a smaller offset between the electron quasi-Fermi level $\left(E_{F, n}\right)$ and the conduction band $\left(E_{\mathrm{cb}}\right)$, that is, a higher electron density at $\mathrm{TiO}_{2}$, and larger driving forces for the interfacial recombination. While a short dipping time was used in this experiment, the $R_{\mathrm{ct}}$ values of the three devices (A, C, and $\mathrm{E}$ ) become similar. As shown in Figure $5 \mathrm{~b}$, all devices have a 
larger value of $R_{\mathrm{ct}}$ than of $R_{\mathrm{t}}$, indicating an effective collection of photogenerated charge carriers in the dye-sensitized heterojunction. Device $\mathrm{D}$ has the smallest $R_{\mathrm{ct}}$ among these devices at an identical $R_{\mathrm{t}}$, implying that the recombination process is amplified by the co-adsorbent NHOOP. This result can be attributed to an augmented trapped electron density when NHOOP is co-grafted, compared to sensitizer alone or grafting C101/ DINHOP.

Based on the results found for $R_{\mathrm{ct}}$ and $C_{\mu}$ we can obtain information on the interfacial recombination lifetime in the photovoltaic devices. A slightly increased apparent electron lifetime $\tau_{\mathrm{n}}$ was observed for devices $\mathrm{E}$ and $\mathrm{F}$ when the co-adsorbent DINHOP was used compared to that of devices in which dye was used alone (devices $A$ and $B$ ). A largely decreased $\tau_{n}$ in the devices with co-adsorbent NHOOP (devices $C$ and D) was observed and is illustrated in Figure $5 c$, indicating that the co-adsorbent has an obvious influence on the interfacial charge recombination process due to the recombination centers introduced onto the $\mathrm{TiO}_{2}$ nanoparticles during the adsorption procedure.

\section{Conclusions}

We characterize the surface of $\mathrm{TiO}_{2}$ films onto which a ruthenium sensitizer dye, C101, is adsorbed with DINHOP or NHOOP as co-adsorbents. The characterization is done by using PES and EIS techniques. The co-adsorbents decrease the amount of dye molecules by about $30-40 \%$. Each dye molecule is replaced by about three NHOOP molecules or two DINHOP molecules, respectively. Notably, PES studies indicate that the ligands of the dye molecules containing the thiophene units point out from the $\mathrm{TiO}_{2}$ surface, in comparison to the NCS group. EIS studies reveal that the DINHOP and NHOOP co-adsorbents have different influence on the charge carrier's interfacial recombination induced by surface modification. Co-adsorption of DINHOP (with phosphinic acid as anchoring group) with C101 substantially increased the power output of the cells, mainly due to retardation of the interfacial recombination of photogenerated charge carriers. The phosphonic acid of $\mathrm{NHOOP}$ has a strong binding strength to the $\mathrm{TiO}_{2}$ surface, offering surface trap states onto the metal oxide, and thus augments the charge recombination even though the insulator property of this molecule can retard this process.

\section{Experimental Section}

\section{Materials}

All solvents and reagents, unless otherwise stated, were of analytical grade and used as-received. Guanidinium thiocyanate (GNCS, $\mathrm{NH}_{2} \mathrm{C}(\mathrm{NH}) \mathrm{NH}_{2} \cdot \mathrm{HSCN}$ ), N-butylbenzimidazole (NBB), and 3-methoxypropionitrile (MPN, $\mathrm{CH}_{3} \mathrm{OCH}_{2} \mathrm{CH}_{2} \mathrm{CN}$ ) were purchased from Fluka. MPN was distilled before use. Co-adsorbent bis-(3, 3-dimethylbutyl)-phosphinic acid (DINHOP) and C101 dye were synthesized as described previously. ${ }^{[7,10]}$

\section{Synthesis of 3, 3-dimethylbutyl-phosphonic acid}

3,3-Dimethyl butyl-phosphonic acid diethylester was prepared according to a literature procedure ${ }^{[9]}$ to a suspension of anhydrous chromium(II) chloride $(7.38 \mathrm{~g}, 60.0 \mathrm{~mm})$ in dry DMF $(180 \mathrm{~mL})$ under argon was added dropwise a solution of ethylenediamine $(7.21 \mathrm{~g}$, $120.0 \mathrm{~mm})$ in DMF $(60 \mathrm{~mL})$. Vinylphosphonic acid diethylester $(15.8 \mathrm{~g}, 96.0 \mathrm{~mm})$ was added in one portion, then tert-butylbromide $(3.29 \mathrm{~g}, 24.0 \mathrm{mmol})$ in DMF $(60 \mathrm{~mL})$ was added dropwise with continuous stirring. The reaction mixture was stirred for $4 \mathrm{~h}$ at room temperature, then heated to $80^{\circ} \mathrm{C}$. The reaction mixture was poured into water $(400 \mathrm{~mL})$ and extracted with diethylether $(3 \times 250 \mathrm{~mL})$. The combined ether extracts were washed with water $(2 \times 200 \mathrm{~mL})$, dried with magnesium sulfate, and filtered. Ether was distilled from the filtrate and the residue was distilled under reduced pressure to give (3,3-dimethylbutyl)-phosphonic acid diethylester $(4.57 \mathrm{~g}, 86 \%)$. (3, 3-Dimethylbutyl)-phosphonic acid diethylester $(4.50 \mathrm{~g})$ was hydrolyzed according to McKenna et al. using trimethylbromosilane $(6.23 \mathrm{~g})$, affording (3,3-dimethylbutyl)-phosphonic acid $(3.36 \mathrm{~g}, 100 \%) .^{[19,20]}$

\section{PES characterization}

Quantitative characterization was performed with an in-house ESCA 300 spectrometer, using monochromated AlKa radiation $(1486.7 \mathrm{eV})$ and calibrated for cross-section and analyzer transmission. ${ }^{[21]}$ The electron take-off angle was $90^{\circ}$. The samples were analyzed at a pressure in the range $10-10 \mathrm{mbar}$. The spectra were energy calibrated with respect to the substrate signal (Ti2p3/2). The quantification of $\mathrm{C} 101$ was obtained by measuring the Ru $3 \mathrm{~d}$ signal versus the Ti2p substrate signal and comparing the different values to that obtained for the sample sensitized for $24 \mathrm{~h}$ with C101 dye only. This procedure is well defined and accounts for variations in the exact sample position with respect to the X-ray source and the analyzer as well as in the X-ray intensity. However, note that it may slightly underestimate the amount of dye for samples with a coverage far from a monolayer since the damping of the substrate signal decreases. In the present study this error was about $10 \%$ for the samples with the lowest coverage and smaller for samples with higher coverages and for samples with coadsorbents.

\section{Device fabrication}

The fabrication of DSC devices was done similar to our previous report. ${ }^{[20]}$ A $6 \mu \mathrm{m}$ transparent layer of $20 \mathrm{~nm}$-sized $\mathrm{TiO}_{2}$ particles was screen-printed onto a fluorine-doped $\mathrm{SnO}_{2}$ (FTO) conducting glass electrode. The preparation of transparent $\mathrm{TiO}_{2}$ film was described previously. ${ }^{[10]}$ The dye solution used was $300 \mu \mathrm{M}$ C101 with and without co-adsorbents (unless otherwise stated with DINHOP or NHOOP as co-adsorbents, with a molar ratio of $4: 1$ ) in a mixture of acetonitrile and tert-butyl alcohol $(1: 1, v / v)$. The two electrodes (the $\mathrm{TiO}_{2}$ photoanode and platinized counter electrode) were separated by a $25 \mu \mathrm{m}$ thick Surlyn hot-melt gasket and sealed by heating. The low-volatile electrolyte composition was: $1.0 \mathrm{M} \mathrm{1,3-dime-}$ thylimidazolium iodide (DMII), $0.15 \mathrm{M} \mathrm{I}_{2}, 0.5 \mathrm{M} \mathrm{NBB}$, and $0.1 \mathrm{M}$ GNCS in MPN. For comparison, the dye dipping experiments were carried out under two different conditions, that is, a short dipping time (device A, $30 \mathrm{~min}$ for $\mathrm{C} 101$, devices $\mathrm{C}$ and $\mathrm{E}, 90 \mathrm{~min}$ for $\mathrm{C} 101$ / DINHOP or C101/NHOOP, respectively), and a long dipping time (18 $\mathrm{h}$ for all dye solutions, device B, D and F for C101, C101/ DINHOP, and C101/NHOOP, respectively). The prepared dye-stained photoanode DSC devices were kept in dark at room temperature 
for 1 day, and a further treatment, that is, light soaking at $60{ }^{\circ} \mathrm{C}$ for $24 \mathrm{~h}$, was performed before subjecting the devices to photovoltaic measurements.

\section{Photovoltaic characterization}

A $450 \mathrm{~W}$ xenon light source (Oriel, USA) was used to give an irradiance of $100 \mathrm{~mW} \mathrm{~cm}^{-2}$ [the equivalent of one sun at air mass (AM) 1.5] at the surface of the solar cells. The spectral output of the lamp was matched in the region of $350-750 \mathrm{~nm}$ with the aid of a Schott K113 Tempax sunlight filter (Präzisions Glas \& Optik GmbH, Germany) so as to reduce the mismatch between the simulated and true solar spectra (less than $2 \%$ ). The current-voltage characteristics of the cell under these conditions were obtained by applying external potential bias to the cell and measuring the generated photocurrent with a Keithley model 2400 digital source meter (Keithley, USA). A similar data acquisition system was used to control the incident photon-to-current conversion efficiency (IPCE) measurement. A white light bias ( $1 \%$ sunlight intensity) was applied onto the sample during the IPCE measurements. The devices with the photoanode area of $0.2826 \mathrm{~cm}^{2}$ were tested with a metal mask: $0.159 \mathrm{~cm}^{2}$

\section{Electrochemical impedance spectroscopy}

EIS measurements were performed with a PGSTAT30 frequency analyzer from Autolab (Eco Chemie B.V, Utrecht, The Netherlands) together with a Frequency Response Analyzer module providing voltage modulation in the desired frequency range. Z-view software (v2.8b, Scribner Associates Inc.) was used to analyze the impedance data. The EIS experiments were performed at a constant temperature of $20^{\circ} \mathrm{C}$ in the dark. The impedance spectra of the DSC devices were recorded at potentials varying from $-0.8 \mathrm{~V}$ to $-0.35 \mathrm{~V}$ at frequencies ranging from $0.05 \mathrm{~Hz}$ to $100 \mathrm{KHz}$, the oscillation potential amplitude being adjusted to $10 \mathrm{mV}$. The photoanode $\left(\mathrm{TiO}_{2}\right)$ was used as the working electrode and a platinum counter electrode (CE) was used as both the auxiliary electrode and the reference electrode. These obtained spectra were fitted (error $<5 \%$ ) with a transmission line model. ${ }^{[12,13]}$

\section{Acknowledgements}

Financial support from the Swiss National Science Foundation is gratefully acknowledged. M.G. thanks the European Research Council (ERC) for an Advanced Research Grant (ARG 247404) funded under the "Mesolight" project. M.W. thanks the National Basic Research Program of China (973 Program, 2011CBA00703), the NSFC (20903030, 201173091), the Talents Recruitment Program of HUST and the CME with the Program of New Century Excellent Talents in University (NCET-10-0416), and the Fundamen- tal Research Funds for the Central Universities, HUST: 2011TS021 for financial support. S.P. and H.R. thank the Swedish Research Council and the Swedish Energy Agency for financial support.

Keywords: photovoltaics · self-assembly $\cdot$ semiconductors spectroscopy $\cdot$ surface analysis

[1] M. A. Green, K. Emery, D. L. King, S. Igari, W. Warta, Prog. Photovolt: Res. Appl. 2003, 11, 347.

[2] B. O'Regan, M. Grätzel, Nature 1991, 353, 737.

[3] G. Li, V. Shrotriya, J. Huang, Y. Yao, T. Moriarty, K. Emery, Y. Yang, Nat. Mater. 2005, 4, 864.

[4] K. Mutolo, E. Mayo, B. Rand, S. Forrest, M. Thompson, J. Am. Chem. Soc. 2006, 128, 8108.

[5] M. K. Nazeeruddin, F. De Angelis, S. Fantacci, A. Selloni, G. Viscardi, P. Liska, S. Ito, B. Takeru, M. Grätzel, J. Am. Chem. Soc. 2005, 127, 16835

[6] Y. Chiba, A. Islam, Y. Watanabe, R. Komiya, N. Koide, L. Han, Jpn. J. Appl. Phys. Part 2 2006, 45, L638.

[7] F. Gao, Y. Wang, D. Shi, J. Zhang, M. Wang, X. Jing, R. Humphry-Baker, P. Wang, S. M. Zakeeruddin, M. Grätzel, J. Am. Chem. Soc. 2008, 130 10720.

[8] a) C. Chen, M. Wang, J. Li, N. Pootrakulchote, C. Alibabaei, J. Decoppet, J. Tsai, C. Grätzel, C. Wu, S. Zakeeruddin, M. Grätzel, ACS Nano 2009, 3, 3103; b) A. Yella, H. Lee, H. Tsao, C. Yi, A. Chandiran, M. Nazeeruddin, E. Diau, C. Yeh, S. Zakeeruddin, M. Grätzel, Science 2011, 334, 629.

[9] T. Marinado, M. Hahlin, X. Jiang, M. Quintana, E. M. J. Johansson, E. Gabrielsson, S. Plogmaker, D. Hagberg, G. Boschloo, S. M. Zakeeruddin, M. Grätzel, H. Siegbahn, L. Sun, A. Hagfeldt, H. Rensmo, J. Phys. Chem. C 2010, 114, 11903

[10] M. Wang, X. Li, H. Lin, P. Pechy, S. M. Zakeeruddin, M. Grätzel, Dalton Trans. 2009, 10015

[11] P. Wang, S. Zakeeruddin, R. Humphry-Baker, J. E. Moser, M. Grätzel, Adv. Mater. 2003, 15, 2101

[12] M. Wang, C. Grätzel, S. Moon, R. Humphry-Baker, N. Rossier-Iten, S. M. Zakeeruddin, M. Grätzel, Adv. Funct. Mater. 2009, 19, 21633

[13] J. Bisquert, V. Vikhrenko, J. Phys. Chem. B 2004, 108, 2313.

[14] J. Bisquert, D. Cahen, G. Hodes, S. Rühle, A. Zaban, J. Phys. Chem. B 2004, 108, 8106.

[15] J. Bisquert, Phys. Chem. Chem. Phys. 2008, 10, 49

[16] Q. Wang, Z. Zhang, S. M. Zakeeruddin, M. Grätzel, J. Phys. Chem. C 2008, $112,7084$.

[17] J. Bisquert, J. Phys. Chem. B 2002, 106, 325.

[18] A. J. Bard, L. Faulkner, Electrochemical Methods: Fundamentals and Applications, 2nd ed., Wiley, New York, 2001.

[19] H. Tashtoush, R. Sustmann, Chem. Ber. 1993, 126, 1759.

[20] C. McKenna, M. Higa, N. Cheung, M. McKenna, Tetrahedron Lett. 1977, $18,155$.

[21] U. Gelius, B. Wannberg, P. Baltzer, H. Fellner-Feldegg, G. Carlsson, C.-G. Johansson, J. Larsson, P. Münger, G. Vegerfors, J. Electron Spectrosc Relat. Phenom. 1990, 52, 747.

Received: September 2, 2011

Revised: October 27, 2011

Published online on January 2, 2012 